\title{
Espectroscopia para o ensino médio utilizando a placa arduino
}

\section{RESUMO}

Gleyce Kelly

kellymesquitafis@hotmail.com

0000-0002-0539-445

Universidade Federal do Piau

Departamento de Física, Teresina, Piauí,

Brasil.

\section{Dicleyson Rocha}

dicleysonrocha@gmail.com

0000-0002-6778-0852

niversidade Federal do Piaú,

Departamento de Física, Teresina, Piauí,

\section{Renato Germano}

rgermano@ufpi.edu.br

Universidade Federal do Piaui, Departamento de Física, Teresina, Piauí, Brasil.
O ensino de Física Moderna no Ensino Médio é pouco abordado pelos professores, principalmente nas escolas públicas; neste trabalho, propomos aos professores uma abordagem prática de desenvolver alguns conteúdos dessa área da Física e assim aplicá-los de forma significativa no processo de ensino e aprendizagem. Propomos a construção de um experimento de baixo custo, utilizando a placa Arduino, que introduza alguns conceitos de Física Moderna, mais especificamente um espectrofotômetro caseiro. Mostramos todos os passos, desde a construção do experimento até sua programação computacional; realizamos algumas medidas a fim de calibrá-lo e obtermos o espectro de absorção de extrato de clorofila, que está de acordo, qualitativamente, com os princípios físicos envolvidos na espectroscopia.

PALAVRAS-CHAVE: Arduino. Espectrofotômetro. Física Moderna. 


\section{INTRODUÇÃO}

Os avanços tecnológicos que se nos apresentaram nas últimas décadas têm sido, de certo modo, assustadores, posto que um cientista que viveu há cem anos jamais poderia imaginar tais avanços em tão curto intervalo de tempo em áreas tais como: Medicina, Física Experimental, Ciência dos Materiais, Telecomunicações etc. Entre os grandes avanços, destacamos a descoberta da Luz; esta serviu como principal instrumento para o desenvolvimento da ciência em geral, dando margem a importantes descobertas, desde a elaboração de teorias a respeito de sua natureza (teoria quântica) até o descobrimento de inúmeros elementos químicos. Deste modo, com o desenvolvimento da ciência, a Luz também possibilitou a interação interdisciplinar entre muitos ramos da ciência, a respeito da espectroscopia.

Considerando sua importância para o desenvolvimento da ciência, ressalte-se a necessidade de tornar conhecida a evolução da história da luz, bem como as técnicas que possibilitaram essa evolução, pelo público em geral. Com base nisso, o ano de 2015 foi escolhido como o Ano Internacional da Luz, uma iniciativa da Organização das Nações Unidas, para aumentar a consciência de como as tecnologias ópticas podem promover desenvolvimento sustentável e fornecer soluções para os desafios mundiais em energia, educação, agricultura, comunicações e saúde (LIGHT, 2015).

A luz pode ser considerada como algo que nos permite ver, contudo, apesar de sua importância, por muito tempo, o seu estudo foi limitado ao estudo da visão. No entanto, em 1666, o famoso físico inglês Isaac Newton realizou a sua famosa experiência de decomposição da luz, proveniente do Sol, o que daria base para a elaboração de uma teoria que perduraria por vários anos, por ocasião do prestígio de Newton, a teoria corpuscular da luz. Newton percebeu em tal experiência que, ao atravessar um feixe de luz branca, proveniente do Sol, em um prisma de vidro, a luz passava a ser decomposta, formando uma espécie de arco-íris. Ao utilizar um segundo prisma em conexão com a luz decomposta, notou que esta voltava ao seu estado inicial na forma de luz branca. Para ele, a luz era um fluxo ordenado de diversas partículas de cores diferentes que se deslocavam sem um movimento retilíneo, explicando a reflexão e a refração de acordo com sua teoria corpuscular.

Por sua vez, Christian Huygens acreditava que a luz era uma perturbação que se propagava com velocidade constante no então acreditado Éter luminífero. 0 prestígio que Newton exercia sobre a comunidade científica fez com que a teoria de Huygens ficasse esquecida por alguns anos, até que, no início do século XIX, com a invenção de novos aparelhos ópticos, sua teoria encontraria novos adeptos, permitindo que pudessem ser medidos com precisão dois fenômenos de caráter ondulatórios: - a interferência e a difração da luz (BEM-DOV, 1996).

A teoria de Huygens passou a ser aceita e perdurou por longos anos, até que, em 1905, Albert Einstein afirmou, com base nas observações de que a emissão e a absorção de ondas eletromagnéticas apresentavam um comportamento diferente para a luz, em que se verificava que a energia de uma onda eletromagnética era emitida e absorvida em pacotes semelhantes a partículas com energias (chamado de efeito fotoelétrico); ou seja, que a luz se comporta como um fluxo discreto de pacotes de energia, chamados de fótons ou quanta, e faz com que a luz passe a ter 
O desenvolvimento da teoria quântica possibilitou esclarecer muitas questões, nas quais a Mecânica Clássica e o Eletromagnetismo não tiveram êxito ao explicar. No entanto, ressalte-se que o famoso experimento da decomposição da luz realizado por Newton possibilitou um avanço significativo da Química, e da Física, mesmo sem o conhecimento da teoria quântica (YOUNG e FREEDMAN, 2009). No ano de 1814, o alemão Joseph Fraunhofer reproduziu a experiência realizada por Newton no século XVII, utilizando um prisma e grades de difração, Fraunhofer obteve um espectro da luz solar mais intenso e ampliado, o que possibilitou a observação da descontinuidade do espectro da luz solar: a existência de inúmeras linhas escuras sobre as cores do espectro. Fraunhofer não sabia explicar o motivo pelo qual essas linhas apareciam, ainda assim realizou várias experiências com materiais excitados que emitiam luz, e notou que esses materiais incandescentes possuíam espectros discretos, formados por linhas brilhantes que correspondiam às linhas negras obtidas pelo espectro da luz solar. Com o auxílio de um telescópio, ele observou que os espectros da Lua e dos planetas eram idênticos ao espectro da luz solar, ao passo que as estrelas apresentavam um espectro exclusivo.

Por volta do ano de 1859 na Alemanha, o químico Robert Wilhelm Bunsen associou-se com o físico Gustav Robert Kirchhoff para a construção de um espectroscópio que apresentou grandes contribuições para a Física e a Química. Ao analisar o espectro de uma chama contendo sódio, Kirchhoff pôde observar que as linhas amarelas emitidas pela chama coincidiam com determinadas linhas negras observadas no espectro da luz solar. Kirchhoff chegou à conclusão de que o sódio gasoso emite e absorve luz de mesma energia, o que o levou a deduzir a existência de sódio na composição do Sol.

Essa descoberta deu margem à catalogação de inúmeros elementos químicos até então desconhecidos, contribuindo também para o desenvolvimento da Astronomia no estudo de estrelas e da composição do Universo, surgindo, deste modo, a Espectroscopia. A espectroscopia possibilitou a descoberta do hélio no Sol, o qual só foi encontrado na Terra vinte e sete anos depois, mostrando a importância da espectroscopia no estudo da constituição da matéria. Em 1885, o matemático suíço Johann Jakob Balmer, obteve uma expressão matemática que descrevia os espectros de emissão ou absorção do hidrogênio (FILGUEIRAS, 1996).

\section{Física Moderna no Ensino Médio}

Sabe-se que uma das dificuldades de se trabalhar com ciências em sala de aula consiste na complexidade e problemática advindas de diversos fatores socioculturais, econômicos, e de fatores provenientes das mudanças de valores, ao longo do tempo, situados no contexto escolar, além das metas estabelecidas pelos currículos para a educação em ciências (BORGES, 2002). De acordo com as orientações curriculares para o Ensino Médio, a Interdisciplinaridade se faz necessária para o desenvolvimento da competência crítico analítica, e não pode ser confundida com o trabalho coletivo das disciplinas escolares, mas na máxima exploração dos limites e potencialidades de cada área do conhecimento (BRASIL, 2006).

Especificamente em Física, tais potencialidades podem ser adquiridas com o auxílio de métodos e estratégias que levem à aprendizagem significativa, como, 
et al., 2002). Outra forma de adquirir tais potencialidades é a utilização de experimentos que façam do aluno um agente ativo e comprometido com a busca de respostas.

Contudo, em Física Moderna, a dificuldade está no elevado custo dos equipamentos e laboratórios específicos para a realização de atividades experimentais, fazendo com que propostas de viabilização de laboratórios tornem efetivo o ensino de Física Moderna (LUDKE, 2010; ARRUDA e FILHO, 1991).

De acordo com os Parâmetros Curriculares Nacionais para o Ensino Médio, a incorporação à cultura e integrada como instrumento tecnológico; esse conhecimento tornou-se indispensável à formação da cidadania contemporânea. Se faz necessário também que essa cultura em Física inclua a compreensão do conjunto de equipamentos e procedimentos, técnicas ou tecnológicos do cotidiano, social e profissional (BRASIL, 1999).

Nessa perspectiva, a espectroscopia pode contemplar perfeitamente essa orientação no ensino de Física Moderna, por ter o caráter interdisciplinar como exemplo da interação da radiação com a matéria, conforme podemos ver em Gomes et al. (1996); Leite e Prado (2012); Savall-Alemany et al. (2014); Ludke (2010); Cavalcante e Benedetto (1999). Desta forma, pode-se destacar o uso de espectroscópios e espectrofotômetros.

Neste artigo, apresentamos um espectrofotômetro, construído com a finalidade de suprir a problemática existente, no que diz respeito à construção de instrumentos de baixo custo e que possuam boa eficiência na realização de medidas comparáveis aos modernos e sofisticados aparelhos utilizados em pesquisas cientificas. Realizamos medidas de extrato de Clorofila no sentido de mostrar sua utilidade na exemplificação de alguns assuntos de Física Moderna.

\section{O espectrofotômetro}

Os Espectrofotômetros são equipamentos que têm como princípio básico para o seu funcionamento medir a absorção de radiação de diferentes comprimentos de onda (LORETO et al, 2008). Ou seja, estes utilizam uma rede de difração ou um prisma para dispersar um feixe luminoso em suas ondas constituintes. Logo, se esse feixe é composto por mais de um comprimento de onda, forma-se um espectro luminoso.

Esses aparelhos permitem a variação contínua do comprimento de onda e a medição ao longo de toda região espectral (uma lâmpada de deutério para a região UV e uma lâmpada de tungstênio-halogênio para a região do visível) dos ângulos nos quais se dá a adsorção para cada cor, obtendo assim um tipo de "assinatura da substância analisada", como um gás por exemplo.

Portanto, esses equipamentos são de extrema importância em caracterização de materiais, e bastante útil na investigação da composição molecular ou atômica de diversas substâncias. Eles também são chamados de espectrômetros dispersivos. A maioria dos instrumentos cobre a escala de 190-940 nm (HEINZHELMUT, 1992). Uma das formas de trabalhar com experimentos de Física Moderna, mais especificamente o espectrofotômetro, sem a necessidade de equipamentos dispendiosos, seria com a utilização da placa Arduino.

O Arduino no ensino de Física 
O Arduino é uma plataforma de hardware opensource, construída para promover interface física entre o ambiente e o computador. Uma das vantagens do Arduino é a facilidade de programação, versatilidade e baixo custo. O Arduino é basicamente um microcontrolador constituído de um microprocessador, memória e periféricos de entrada (sensores de temperatura, luz, som, umidade etc.) e saída (leds, motores, displays, autofalantes etc) (ARDUINO, 2015; MCROBERTS, 2011).

Recentemente observamos uma crescente utilização dessa plataforma no ensino de Física, como no estudo do movimento harmônico amortecido de uma lâmina, e no estudo de trocas radioativas de energia, utilizando um termistor (DE SOUZA, 2011). Pode-se, também, incorporar o Arduino em montagens tradicionalmente utilizadas nos laboratórios didáticos, como, por exemplo, os circuitos elétricos, no estudo de carga e descarga de capacitores (CAVACANTE et al., 2011); utilizá-lo acoplando sensores de pressão manométrica para o estudo da comparação, entre a medida de pressão de um sistema gasoso e a pressão atmosférica local (DA ROCHA E GUADAGNINI, 2013); no estudo numérico da aceleração de corpos (DA ROCHA E MARANGHELLO, 2013), entre outras aplicações.

Assinale-se que a placa Arduino é um dispositivo de fácil acesso e com um custo benefício considerável, em que, além do professor, o aluno poderá utilizá-la em diversos experimentos de Física, e, assim, contribuir para o aumento do interesse pela disciplina Física. Portanto, neste trabalho, propomos a construção de um espectrofotômetro de baixo custo, utilizando a placa Arduino. Nas próximas seções apresentamos a montagem experimental, os resultados e as considerações finais.

\section{Montagem experimental}

Observe-se, a seguir, a lista de materiais utilizados para a construção do experimento:

- Uma placa Arduino (nano) (Figura 2a).

- O sensor de luminosidade digital utilizado foi o BH1750FVI (Figura 2b), que mede a intensidade de iluminação em lux, que corresponde à incidência perpendicular de um lúmen em uma superfície de 1 metro quadrado. Na Figura 1 , podemos ver a resposta espectral desse sensor como função do comprimento de onda.

Figura 1 - Resposta espectral do sensor bh1750 como função do comprimento de onda.

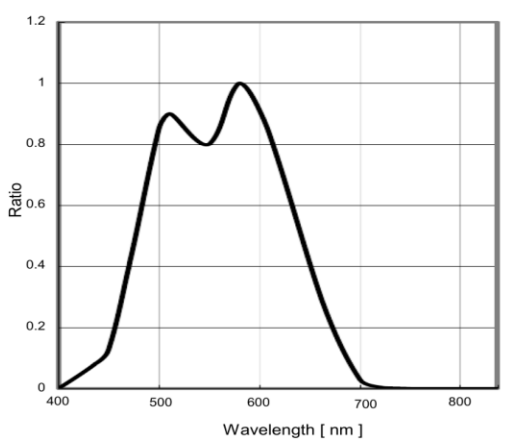


(Fonte:

Disponível

em:

http://rohmfs.rohm.com/en/products/databook/datasheet/ic/sensor/light/bh17 50fvi-e.pdf)

- Motor de passo bipolar retirado de um mecanismo de DVD e um controlador de motor (Motor Driver IC) L293D (Figura 2c).

- Leitor de cartão SD (opcional), para salvar os dados das medidas.

- Uma lâmpada alógena de tungstênio de 100 W de potência.

- Base de madeira, uma lupa, uma grade de difração (CD), anteparos a fim de minimizar a luminosidade desnecessária.

- Porta amostra de plástico (cubeta).

- Compensado para a construção da base.

Figura 2 - a) Placa Arduino nano; b) sensor digital de luminosidade BH1750FVI e c) mecanismo de DVD com motor de passo bipolar.
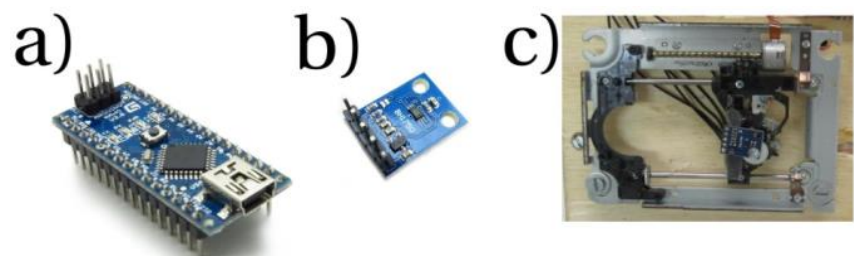

(Fonte: elaboração própria)

A partir do princípio básico de funcionamento de um espectrofotômetro, esquematizamos o experimento da seguinte forma: um feixe de luz branca através da lâmpada de tungstênio; um monocromador (foi utilizado um CD); um porta amostra; um detector de intensidade de iluminação e um Arduino acoplado ao computador, servindo como amplificador de sinal. Na Figura 3, podemos ver a montagem experimental, e, na Figura 4, vemos os detalhes da montagem dos componentes na placa Arduino.

Figura 3 - Montagem experimental do espectrofotômetro de baixo custo.

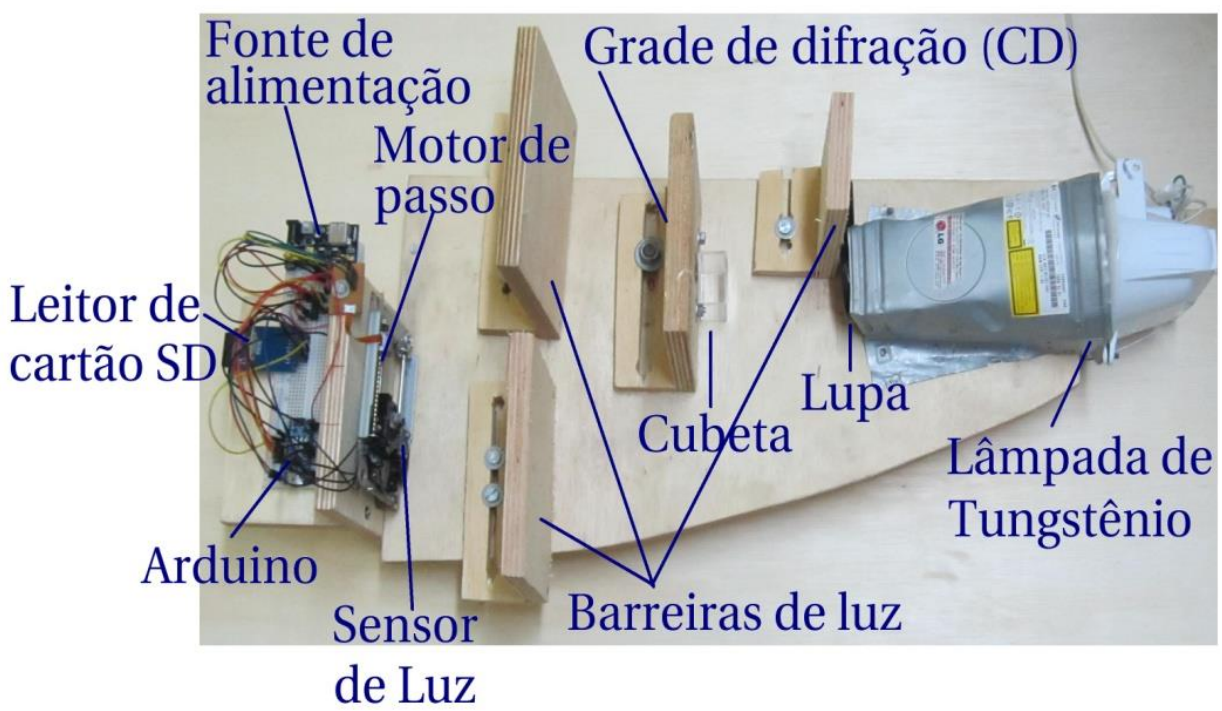


(Fonte: elaboração própria)

Figura 4 - Detalhe da montagem do Arduino e do motor de passo.

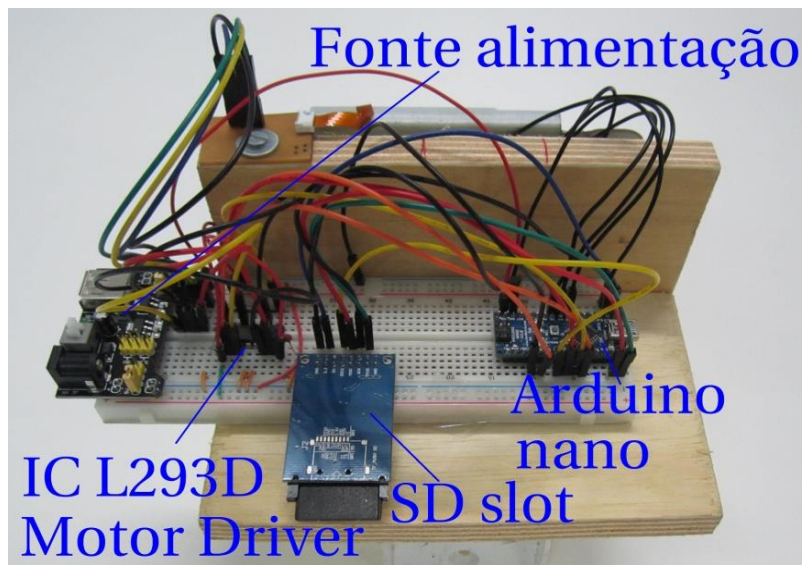

(Fonte: elaboração própria)

Nas Figuras 5, 6 e 7, podemos ver os esquemas de conexão do motor de passo, do sensor de iluminação e do leitor de cartão SD no Arduino, respectivamente. No anexo pode ser visto o código em linguagem $\mathrm{C}$, para o funcionamento do aparato experimental proposto.

Figura 5 - Detalhe da montagem do motor de passo no Arduino.

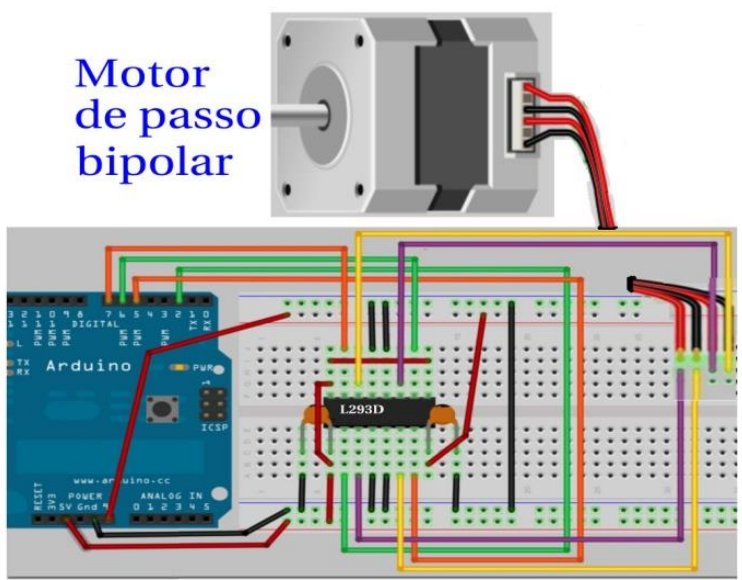


(Fonte: MCROBERTS, 2011)

Figura 6 - Detalhe da montagem do sensor de luz BH1750 no Arduino.

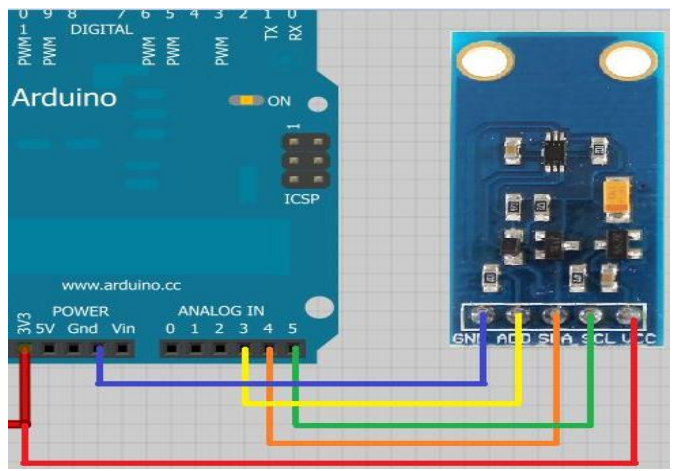

(Fonte: MCROBERTS, 2011)

Figura 7 - Detalhe da montagem do leitor de cartão SD no Arduino

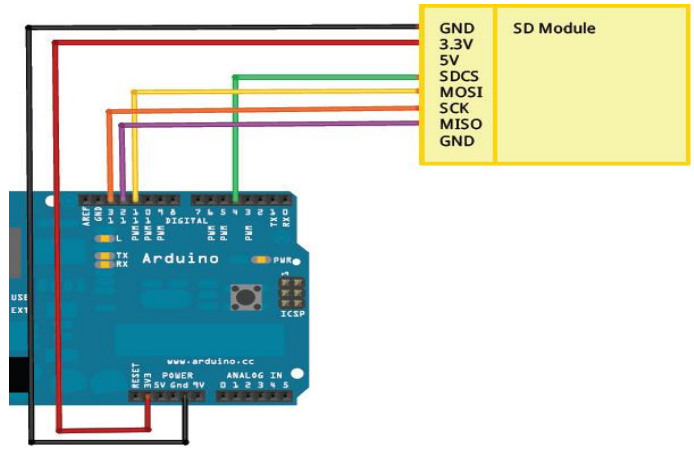

(Fonte: MCROBERTS, 2011)

\section{RESULTADOS}

A lâmpada alógena de tungstênio apresenta um espectro de emissão contínuo, que vai desde os comprimentos de ondas próximos ao ultravioleta até o infravermelho, como podemos ver na Figura 8.

Figura 8 - Distribuição espectral para várias temperaturas de uma lâmpada alógena de tungstênio

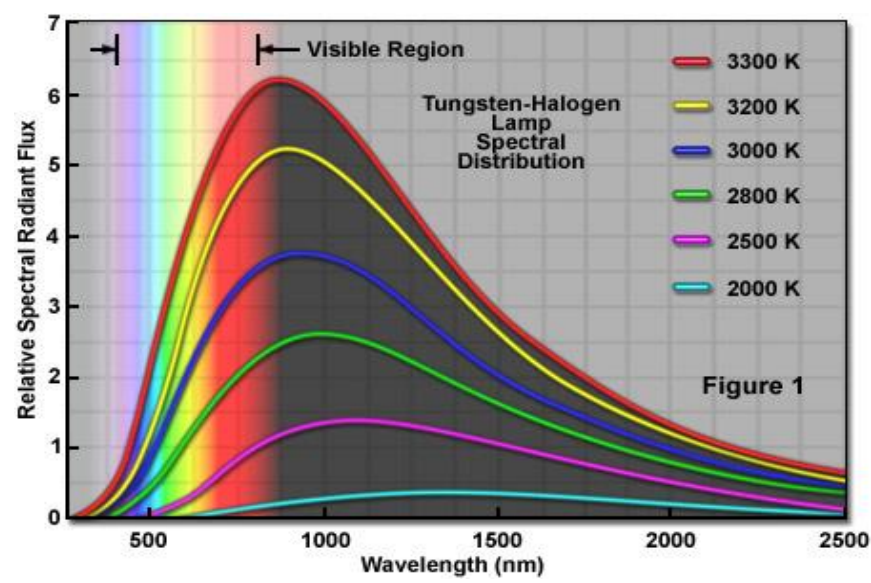


(Fonte:

Disponível

em: http://zeisscampus.magnet.fsu.edu/articles/lightsources/tungstenhalogen.html)

Vimos que o sensor de iluminação utilizado (BH1750) somente capta radiação na região do visível. A intensidade relativa de emissão, como função do comprimento de onda (deslocamento do motor de passo), pode ser vista na Figura 9. Essa distribuição de intensidade da radiação da lâmpada foi obtida sem nenhuma amostra. Podemos observar o perfil do espectro eletromagnético no visível, a figura está normalizada.

Tal resultado está de acordo, pelo menos de forma qualitativa, com os resultados da literatura. Dizemos de forma qualitativa, pois o aparato experimental não é capaz de nos fornecer as grandezas como função do comprimento de onda. Assim, nossos resultados serão expressos em função do deslocamento do motor de passo. Porém, o perfil da intensidade do visível do espectro eletromagnético, mostrado na Figura 9, nos servirá como "padrão", tendo em vista que apenas sabemos que o início se dá próximo do violeta e o final se dá próximo do vermelho.

Figura 9 - Perfil normalizado do espectro eletromagnético como função do deslocamento (comprimento de onda), obtidos pelo aparato experimental com o porta amostra vazio.

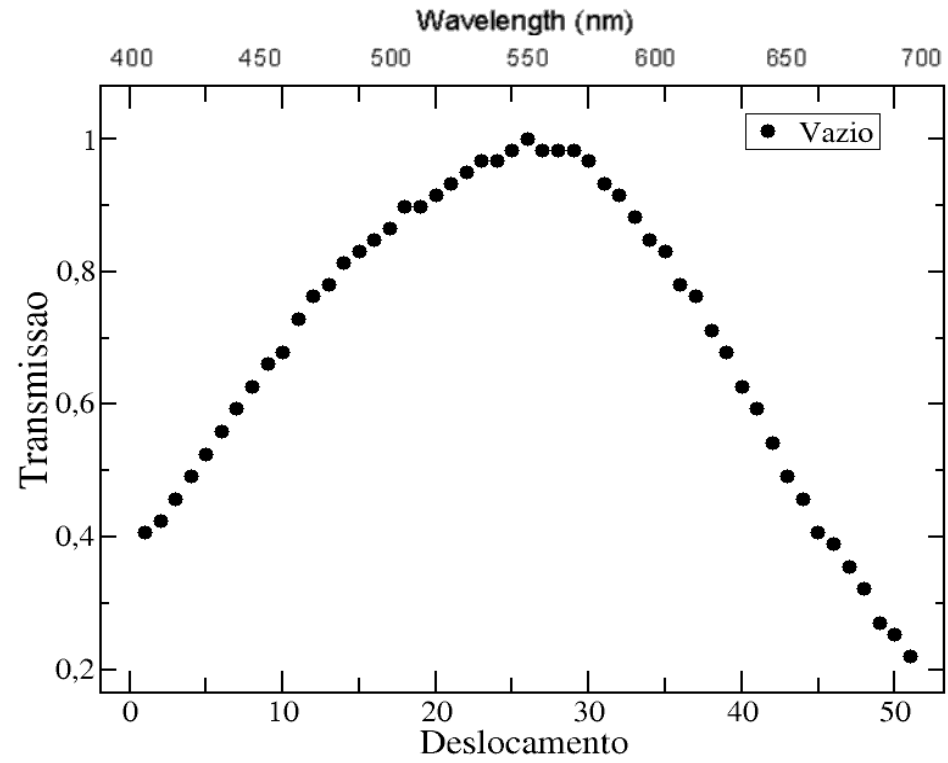

(Fonte: elaboração própria)

Desta forma, para "calibrar", mesmo que qualitativamente, os resultados experimentais, utilizamos dois filtros coloridos, um vermelho e outro azul, os quais podem ser retirados de óculos que servem para visualizar anaglifos (Figura 10a). Na Figura 10b, podemos ver o porta amostra utilizado nas medidas.

Figura 10 - a) Filtros coloridos utilizados como referências; b) cubeta porta amostra utilizada. 


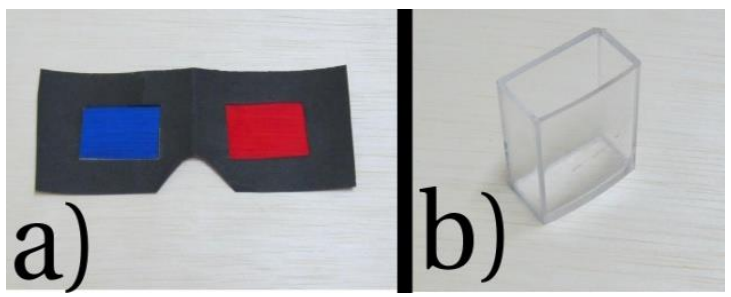

(Fonte: elaboração própria)

Com uma aplicação do espectrofotômetro proposto, realizamos medidas do espectro de transmissão do extrato de clorofila, retirados de folha da mangueira, os resultados obtidos estão apresentados na Figura 11, a seguir.

Figura 11 - Fração de absorção dos filtros vermelho e azul; e do extrato de clorofila.

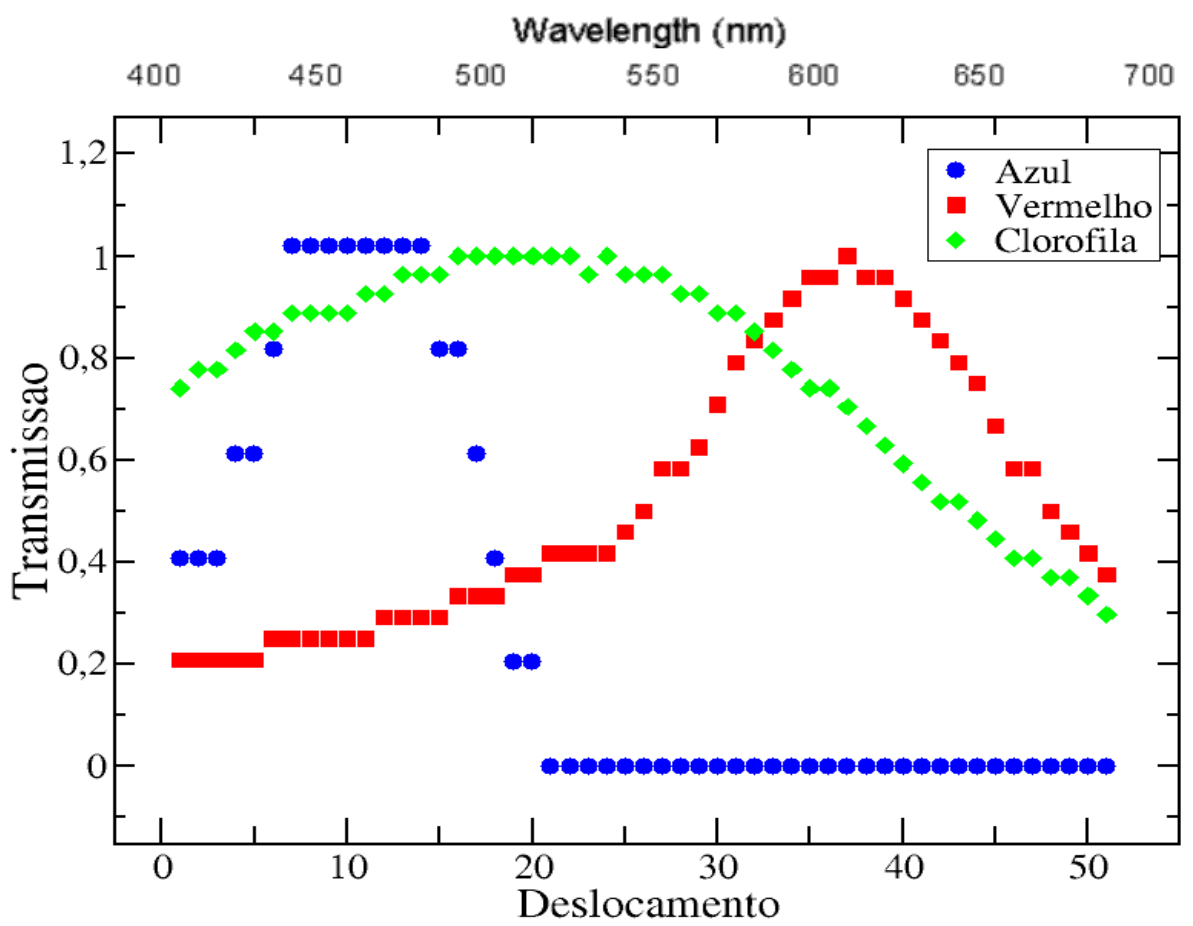

(Fonte: elaboração própria)

Na Figura 11, vemos o espectro de absorção da clorofila, o que nos mostra que os resultados obtidos pelo espectrofotômetro caseiro estão de acordo com os princípios físicos da espectroscopia de absorção; isto é, o espectro de absorção da clorofila deve se localizar entre o vermelho e o azul.

\section{CONSIDERAÇÕES FINAIS}

É inegável a importância da luz para o avanço científico das últimas décadas. Desde os instrumentos ópticos simples, tais como microscópios ópticos, lunetas, telescópios, a sistemas de maior complexidade, que se utilizam das propriedades da interação da radiação com a matéria, tais como o LED, o laser, raios-X. Em razão disso, o ano de 2015 foi escolhido pela Organização das Nações Unidas como o ano internacional da luz. Tal fato proporcionou o aumento da consciência de como as 
tecnologias ópticas podem promover desenvolvimento sustentável e fornecer soluções para os desafios mundiais em energia, educação, agricultura, comunicações e saúde.

Nesse contexto, de instrumentos ópticos, nos deparamos com o chamado espectrofotômetro, um instrumento capaz de estudar os espectros de absorção ou emissão das substâncias. Os princípios físicos de funcionamento de tais instrumentos fazem parte da chamada Física Moderna. Por isso, neste trabalho propomos a construção de um espectrofotômetro de baixo custo, utilizando a placa Arduino, como instrumento facilitador de introdução da Física Moderna no Ensino Médio, principalmente nas escolas da rede pública de ensino. Esperamos que estas escolas trabalhem a interação da radiação com a matéria, porque a utilização de experimentos de Física Moderna é de extrema importância, tanto na divulgação dos fenômenos que envolvem a luz quanto na divulgação científica.

Por fim, é preciso realizar experimentos nas escolas para tornar as aulas mais atraentes e motivadoras, trazer os conceitos e aplicações dos grandes avanços científicos da Física para o que os alunos estudam em sala de aula. Os resultados obtidos por meio do aparato experimental foram satisfatórios, pois apesar de ser de baixo custo, tal aparato é capaz de obter bons resultados qualitativos de espectros de absorção na região do visível.

\section{ANEXO}

\#include <Stepper.h>

\#include <BH1750FVI.h> //biblioteca do sendor de luz.

\#include <Wire.h>

\#include $<$ SD.h $>$

BH1750FVI LightSensor;//variavel do sensor de luz.

File myFile;//variavel para salvar os dados.

$/ /$ motor de passo nos pinos 2, 5, 6 e 7

Stepper stepper(200, 2, 5, 6, 7);//passos para uma volta completa.

float cont $=0 ; / /$ contador para computar os passos.

void setup()

\{

Serial.begin(9600);

//inicia sensor de luz.

LightSensor.begin();

LightSensor.SetAddress(Device_Address_H);//address 0x5C

LightSensor.SetMode(Continuous_H_resolution_Mode2);//para melhor resolucao.

//inicia o cartao SD.

Serial.printIn("Iniciando cartao SD..."); 
pinMode(10, OUTPUT);

if (!SD.begin(4)) \{

Serial.println("Falha na iniciacao!");

return;

\}

Serial.println("Inicializacao concluida.");

//criacao do arquivo.

myFile = SD.open("dadosluz.txt", FILE_WRITE);

//se o arquivo estiver corretor, comeca a gravar os dados:

if (myFile) \{

Serial.println("Iniciando as medidas...");

Serial.println("passos lux");

myFile.println("passos lux");

delay(5000);//tempo para iniciar a coleta de dados.

cont=1;

while(cont $<=52$ )

\{

uint16 t lux = LightSensor.GetLightIntensity();//recebe a intensidade de luz em lux.

stepper.setSpeed(10);//velocidade da varredura.

stepper.step(-5);//tamanho dos passos (precisao das medidas).

//sendo 260 e o tamanho maximo do percurso da amostra

//imprime dados no monitor serial.

Serial.print(cont );

Serial.print(" ");

Serial.println(lux);

//salva dados no cartao.

myFile.print(cont);

myFile.print(" ");

myFile.print ln(lux);

cont $=$ cont $+1 ; / /$ incrementa o contador.

delay(1000);//tempo entre as medidas $(1000=1 \mathrm{~s})$, quanto maior mais lento!

myFile.close();//fecha o arquivo.

Serial.printIn("Fim das medidas."); 
stepper.setSpeed(60);

stepper.step(260);\}

else \{

//se o arquivo nao abrir, imprime a mensagem de erro:

Serial.printIn("Erro na abertura de dadosluz.txt");

\}\}

void loop()

$\{/ /$ nao ha loops. $\}$ 


\title{
Spectroscopy for high school using the aeduino board
}

\begin{abstract}
The teaching of Modern Physics in high school is rarely addressed by teachers, especially in public schools, in this work we propose to teachers a practical approach to develop some content that the physical area and thereby apply them significantly in the process of teaching and learning. We propose to construct a low cost experiment, using Arduino board, which introduces some concepts of Modern Physics, more specifically a home spectrophotometer. We show all the steps, from the construction of the experiment to the computer programming of the same, we made some steps to calibrate it and get the chlorophyll extract absorption spectrum, which is in agreement qualitatively with the physical principles involved in spectroscopy.
\end{abstract}

KEYWORDS: Arduino. Spectrophotometer. Modern Physics. 


\section{AGRADECIMENTO}

Os autores agradecem à CAPES pelo apoio financeiro, através de concessão de Bolsa do Programa Institucional de Bolsa de Iniciação à Docência (PIBID) Física/UFPI.

\section{REFERÊNCIAS}

ARDUINO. Disponível em: https://www.arduino.cc/. Acesso em: jul. 2016.

ARRUDA FILHO, S. M. D. O. Caderno Catarinense de Ensino de Física, v. 8, n. 3, p. 390, dez. 1991.

BEM-DOV, Y. Convite à física. Rio de Janeiro: Jorge Zahar, 1996.

BORGES, A. T. Caderno Brasileiro de Ensino de Física. v. 19, n. 3, p. 291, dez. 2002.

BRASIL. Ministério da Educação (MEC), Secretaria de Educação Média e Tecnológica (Semtec). Parâmetros Curriculares Nacionais para o Ensino Médio. Brasília: MEC/Semtec, 1999.

BRASIL. Orientações Curriculares para o Ensino Médio. Ciências da natureza, matemática e suas tecnologias / Secretaria de Educação Básica - Brasília: Ministério da Educação; Secretaria de Educação Básica, v. 2. 2006.

CAVALCANTE, M. A.; BENEDETTO, A. Revista Brasileira de Ensino de Física, v. 21, n. 3, p. 437, 1999.

CAVALCANTE, M. A.; TAVOLARO, C. R. C.; MOLISANI, E. Física com Arduino para iniciantes. Revista Brasileira de Ensino de Física, v. 33, n. 4, p. 4503, 2011.

DA ROCHA, F. S. GUADAGNINI, P. H. Projeto de um sensor de pressão manométrica para ensino de física em tempo real. Caderno Brasileiro de Ensino de Física, v. 31, n. 1, p. 124-148, 2013.

DA ROCHA, F. S.; MARANGHELLO, G. F.; LUCCHESE, M. M. Acelerômetro eletrônico e a placa Arduino para ensino de física em tempo real. Caderno Brasileiro de Ensino de Física, v. 31, n. 1, p. 98-123, 2013. 
DE SOUZA, A. R. et al. A placa Arduino: uma opção de baixo custo para experiências de física assistidas pelo PC. Revista Brasileira de Ensino de Física, v. 33, n. 1, p. 1702, 2011.

FILGUEIRAS, C. A. L. Química nova na escola, Espectroscopia e química, n. 3, maio 1996.

GOMES, P. R. S. et alii. Revista Brasileira de Ensino de Física, v. 18, n. 4, 1996.

HEINZ-HELMUT. UV-VIS. Spectroscopy and its aplications. Berlim: Springerverlag, 1992.

LEITE, D. de O.; PRADO, R. J. Revista Brasileira de Ensino de Física, v. 34, n. 4, p. 4309, 2012.

LIGHT2015. Disponível em: http://www.light2015.org/Home.html. Acesso em: jul. 2016.

LORETO, É. L. S. et al. Radiações, moléculas e genes: atividades didáticoexperimentais. 1. ed. Ribeirão Preto, SP: Sociedade Brasileira de Genética, 2008.

LUDKE, E. Revista Brasileira de Ensino de Física, v. 32, n. 1, p. 1506, 2010.

LUDKE, E. Um espectrofotômetro de baixo custo para laboratórios de ensino. Revista Brasileira de Ensino de Física, v. 32, n. 1, p. 1506, 2010.

MAGALHÃES, M. et alii. Revista Brasileira de Ensino de Física, v. 24, n. 4, p. 489, 2002.

MCROBERTS, M. Arduino básico. São Paulo: Novatec, 2011.

SAVALL-ALEMANY, F. et alii. Revista Brasileira de Ensino de Física, v. 36, n. 4, p. 4302, 2014.

YOUNG, H. D.; FREEDMAN, R. A. Física IV: ótica e Física Moderna, 12. ed. São Paulo: Pearson, 2009. v. 4. 
Recebido: 2016-05-09

Aprovado: 2017-05-06

DOI: 10.3895/rbect.v10n2.3997

Como citar:

KELLY, G.; ROCHA, D.; GERMANO, R. Espectroscopia para o Ensino Médio utilizando a placa Arduino. Revista Brasileira de Ensino de Ciência e Tecnologia, v. 10, n. 2, 2017. Disponível em: $<$ https://revistas.utfpr.edu.br/rbect/article/view/3997>. Acesso em: xxx.

Correspondência: Renato Germano

Av Univesritária sn, UFPI - CCN - Dep. De Física, CEP: 64049-550, Teresina - Piauí.

Direito autoral: Este artigo está licenciado sob os termos da Licença Creative Commons-Atribuição 4.0 Internacional.

\section{(c) (1)}

